\title{
y Palermo
}

Cruce entre películas de gangsters, film noir
y el imaginario del criollismo tanguero

vol 13 / Dic.2015 251-268 pp Recibido: 22-07-2015 - revisado 13-08-2015 - aceptado: 22-09-2015 


\section{MONTE CRIOLLO AND PALERMO \\ HYBRIDIZATION OF GANGSTER MOVIES, FILM NOIR AND THE IMAGINARY \\ OF CRIOLLISMO AND TANGO TRADITION}

\section{ABSTRACT}

The following paper analyzes Arturo S. Mom's movies Monte criollo (1935) and Palermo (1937) as two examples of the first approaches of Argentine cinema to the genre thriller or crime film. In that sense, I discuss the ways in which these films takes up, on the one hand, some topics and patterns of the film noir and the gangster movie, that is, models of Classical Hollywood Cinema, and on the other, merge these traditions with aspects of contemporary popular culture from Argentina, elements of Criollismo and tango tradition. In this hybridization, some motives that the literary and cinematic traditions had placed in the field of villainy are resignified, for example eloquence and the seduction of a nice voice-that in the gothic and detective fiction tradition were identified with evilness-are now ennobled, based on the premise of the tango singer's heroism. I also try to show how a particular local crime, kidnapping and murder of Eugenio Pereyra Iraola, changes the film representation of criminals at that time, and, furthermore, how these movies discuss female and male archetypes of the time and propose new models of gender identities.

\section{Keywords}

Film noir, crime film, gangster, Eugenio Pereyra Iraola, Argentine cinema, eloquence and seduction by voice, female identity, policewoman.

\section{RESUMEN}

El siguiente trabajo analiza las películas Monte criollo (1935) y Palermo (1937), de Arturo S. Mom como dos ejemplos de las primeras aproximaciones del cine argentino al género policial o crime film. En ese sentido, discutimos los modos en que estas películas trabajan, por un lado, con motivos del cine negro y de las películas de gangsters, es decir, los modelos del cine clásico hollywoodense y, por otro, cómo fusionan estas tradiciones con elementos propios de la cultura popular argentina contemporánea, los imaginarios del tango y del criollismo. A partir de esa fusión, algunos elementos que la tradición había colocado en el ámbito de la villanía son resignificados, tal como sucede con el dominio de la voz -que la tradición del gótico y del policial identificaban con el mal-que ahora, a partir de la heroicidad local del cantor de tangos, es ennoblecido. En este sentido, mostramos también de qué modo un crimen local concreto, el secuestro y asesinato de Eugenio Pereyra Iraola, modifica en el cine la representación de los criminales. A su vez, discutimos de qué modo estas películas reelaboran los arquetipos femeninos y masculinos de la época y proponen nuevos modelos de identidades genéricas.

\section{Palabras Clave}

Cine negro, film policial, gánster, Eugenio Pereyra Iraola, cine argentino, uso de la voz, identidad femenina, mujer policía. 


\section{INTRODUCCIÓN}

En Asesinos de papel, Jorge Lafforgue comenta un encuentro con Juan José Sebreli poco después de haber entregado a la imprenta ese libro: el Sebreli de ese relato reprocha con acritud a Lafforgue, uno de los más reconocidos investigadores de literatura y cine policiales argentinos, el haber dejado de lado en el libro la película Monte criollo: "si ustedes hablan del cine argentino con relación al policial supongo que habrán comentado Monte criollo (1935) de Arturo S. Mom. Si no lo hicieron, tiren el libro a la basura. Ya mismo" (Lafforgue y Rivera, 1996, p. 281). Es interesante que precisamente Sebreli, uno de los primeros en discutir en la Argentina las novelas pertenecientes a la serie negra, le haga esta indicación a Lafforgue. Arturo S. Mom es, por cierto, una de las figuras más importantes del cine policial argentino de los comienzos, y varias de sus películas tempranas se encuadran de uno u otro modo dentro del macroconcepto género policial: entre ellas, Loco lindo, que ya en 1936 parodia la tradición de la literatura policial clásica, con Luis Sandrini interpretando a Miguelito, un muchacho de pueblo que se convierte repentinamente en detective para salvar a su amada Carmencita (Anita Jordán) y busca aprender el oficio a partir de la lectura del Manual del perfecto detective. ${ }^{1}$ También Monte criollo y Palermo se inscriben dentro de esta tradición del crime film, con elementos propios del cine negro y de las películas de gangsters. En este trabajo nos centraremos en la discusión de estas dos películas para mostrar de qué manera Mom cruza esas tradiciones genéricas con los imaginarios tanguero y criollista en el contexto del cine argentino clásico e industrial. Asimismo, intentamos mostrar que en esta hibridación de tradiciones Mom construye figuras femeninas que se alejan de los tipos establecidos en el cine de la época.

\section{IDENTIDADES GENÉRICAS Y CRIOLLAS EN LA CONSTRUCCIÓN DE UN MUNDO CRIMINAL ESPECÍFICO}

Monte criollo (1935) narra la historia de un grupo de tres personas que constituyen a un mismo tiempo una sociedad fraudulenta y un triangulo amoroso: Lucy (Nedda Francy), que es presentada en su huida de la policía, Argüello (Francisco Petrone) y Carlos (Florindo Ferrario), dos timadores que se ganan la vida con juegos tramposos de naipes. Ellos constituyen los puntos de la figura geométrica y amorosa, situada al comienzo del film en una geografía portuaria de bajo fondo.

Las habilidades de los dos protagonistas masculinos se complementan a los fines de los negocios fraudulentos; pues Carlos es la voz que atrae al público, mientras que Argüello representa, entre otras cosas, la habilidad con las manos, que sirve para quitarles el dinero a los demás jugadores, que no son otra cosa que ciudadanos honrados: "Con esa voz [de Carlos] y esas manos [de Argüello] se podría llegar lejos", afirma Lucy (en Mom, 1935) y ella misma se constituye, al menos al comienzo, en el cerebro que guía los modos de la articulación verbal y de la destreza manual. El enriquecimiento económico de este grupo de personajes es impulsado por la guía mental de Lucy, que logra conducir a los cuerpos de los tres por el camino llano del éxito económico. Con esta lógica de la fragmentación corporal, la película representa con un sumario (Gaudreault y Jost, 1995, pp. 126-128), que enlaza distintas imágenes de los pies de los tres protagonistas caminando por diversos barrios de la ciudad (Fig. 1), el avance económico de este nuevo cuerpo delictivo: vemos a los protagonistas en su ascenso a través de diferentes salones de lujo creciente, hasta llegar a El Paraíso, una boîte suntuosa en que establecen su negocio clandestino luego de dos años de progreso ininterrumpido. Esta secuencia ha sido 
señalada reiteradamente por la crítica tanto por su valor artístico como simbólico: "La secuencia en que se manifiesta el transcurrir del tiempo a través de primeros planos de los pies de los protagonistas caminando y avanzando en su raid delictivo -reflejado en su ascenso social- es todo un acierto" (Blanco Pazos y Clemente, 2004, p. 2).

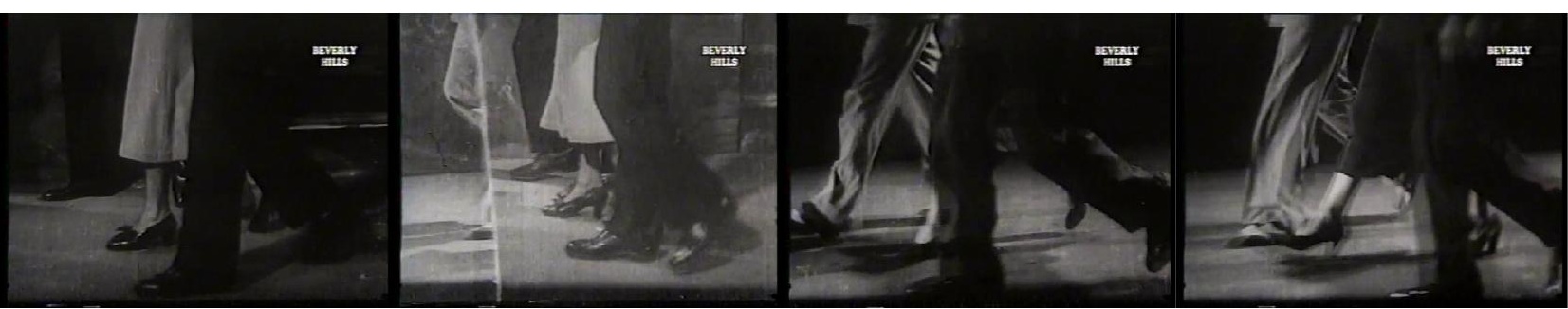

Figura 1. Argüello, Carlos y Lucy avanzan a través de la ciudad y ascienden socialmente gracias a los negocios clandestinos y las estafas (Monte criollo, 1935).

El nombre de la boîte, El Paraíso, implica un tinte ostensiblemente irónico, pues si bien los tres protagonistas han logrado salir de las penurias económicas hasta lograr vivir en la abundancia, este proceso se ha llevado a cabo gracias a sacrificios más que ostensibles, y al menos dos de los tres personajes no se encuentran satisfechos luego del camino recorrido: Argüello y Lucy. Ambos padecen una insatisfacción en el plano amoroso-sentimental. Existe, entonces, una satisfacción por los logros económicos, pero el costo es ingente en el plano afectivo:

Lucy: Y estoy contenta, Argüello. ¿No ve? Ganamos dinero. Vivimos bien. ¿Qué más? Acuérdese de lo que éramos cuando nos encontramos. ¿No ve ahora lo que somos? Y lo que tenemos (...) He ido cambiando, cambiando... Deje mi corazón por mi cuenta.

Argüello: En cambio, nunca ha pensado usted en el hombre en su casa, en el hombre capaz de vivir para usted. Y morir por usted. Nosotros dos, solos, haríamos milagros, si no estuviera Carlos de por medio.

Lucy: Estaría yo.

Argüello: Ya sabría yo cómo arreglármelas con usted. Y lo verá algún día, se lo juro.

Lucy: Buen amigo es usted.

Argüello: Yo no tengo amigos. Yo soy solo. (En Mom, 1935)

Entre la colaboración en los negocios fraudulentos, guiada por los intereses económicos comunes, y el conflicto afectivo, determinado por el choque de intereses amorosos, se desarrollan los vaivenes de la película. Pero ya en el diálogo precedente se deja ver con claridad cuáles son las limitaciones de Argüello en los dos ámbitos. En el enunciado yo soy solo se puede percibir que sus traiciones, presentes y futuras en el ámbito de los afectos -especialmente en su presunta amistad con Carlos- tienen como correlato una concepción igualmente individualista en el ámbito de los negocios. Esto explica, por lo tanto, su violación de las normas de honradez que presuntamente guían el juego de naipes entre él y Carlos -“manos limpias, sin mula, como caballeros de guante blanco", tal como lo formula Carlos (en Mom, 1935). Pero Argüello hace trampa también aquí.

No hay entonces nada en la vida de Argüello que escape al ámbito de la traición, pues todos los pactos son provisorios ${ }^{2}$ y ese su ser solo determina su vida en la totalidad de los ámbitos. 
El contraste con Carlos y con Lucy se evidencia en este sentido con completa nitidez, pues en ellos podemos percibir una separación tajante entre los ámbitos del negocio y del fraude, por un lado, y el ámbito de los afectos y la honradez, por otro. Para ellos, por tanto, los afectos son incompatibles con la trampa, la mentira y la traición. Incluso cuando Carlos en algún momento se deja arrastrar por Argüello y apuesta a Lucy a las cartas, y la pierde, se sigue comportando como un caballero de guante blanco, honradamente, sin mula. No obstante, es visible la censura del film por el hecho de que Carlos ha pasado aquí un límite que no habría debido pasar, pero también es claro que para él se trata todavía de un ámbito que no es el de los negocios, no es el juego sucio de El Paraíso, sino una partida presuntamente honorable con su amigo Argüello -al que ahora comienza a percibir de manera diferente-. En consonancia con estos códigos de Carlos, se comporta Lucy. Esto se comprueba en su relación con Mendieta (interpretado por Domingo Sapelli): en cuanto este personaje ha comenzado a ingresar en su ámbito afectivo, ella ya no tolera que él siga siendo víctima de sus negocios engañosos y le revela el timo que se lleva a cabo en la casa de juego.

La historia y el entramado afectivo planteados aquí por Mom son en muchos aspectos semejantes a los de Palermo, película realizada por este director dos años después (1937). De manera similar a lo que sucede con Carlos cuando pone en peligro a su amada Lucy, el personaje de Adolfo Villanueva (interpretado por José Gola) en Palermo sobrepasa en el juego los límites recomendables y también pone en peligro a su amada, el honor de su familia, su nombre y su propia vida. El personaje de Lucy, en cambio, es comparable con la figura de Ana María Nielsen interpretada también por Nedda Francy-, quien, al igual que Lucy en Monte criollo, es el cerebro del negocio (de la investigación) y también arriesga su amor en estos asuntos criminales. Así, tanto Monte criollo como Palermo entrelazan estos triángulos amorosos con el fraude, el juego y las apuestas. Ambas películas trabajan parcialmente con el imaginario del cine de gangsters estadounidense, pero sitúan la historia en un ambiente nocturno, porteño y portuario. El personaje del criminal es aquel que, como Argüello, es solo, en contraste con el motivo del culto a la mistad que caracterizó al cine argentino de los comienzos -Nobleza gaucha (Cairo, Gunche, Martínez de la Pera, 1915), Perdón, viejita (Ferreyra, 1927), Tango! (Moglia Barth, 1933), Los tres berretines (Sussini, 1933), Prisioneros de la tierra (Soffici, 1938)-. En el cine argentino temprano el verdadero criminal es quien es incapaz de la amistad y vive en un mundo en que no se respetan las lealtades y se propician las traiciones, tal como sucede con Argüello, pero también con los protagonista de Fuera de la ley (Romero, 1937a), Alias Gardelito (Murúa, 1962), El jefe (Ayala, 1958), La Maffia (Torre Nilsson, 1972), solamente por nombrar unos cuantos ejemplos, y en contraste con los hombres del crimen con códigos, como Carlos, pero también en contraste con los protagonistas de Perdón, viejita o La fuga (Saslavsky, 1937), Turbión (Momplet, 1938), e incluso el hijo criminal de El pájaro cantor vuelve al hogar -la segunda historia de No abras nunca esa puerta (Christensen, 1952)-, a los que la historia finalmente redime precisamente por esas lealtades y valores afectivos. En los dos films de Mom, vemos una renovación de las representaciones del delito, en que los nuevos criminales van reemplazando a los antiguos: los cuchilleros van cediendo su lugar para dar paso a los pistoleros. Esto se puede corroborar con claridad tanto en Monte criollo como en Palermo. Ya casi han desaparecido los cuchilleros de las orillas, para dar lugar a los hombres que portan armas de fuego, como Mendieta, quien en su disputa con Argüello lo amenaza con matarlo de un tiro: "no sé por qué no lo vuelco de un tiro" (en Mom, 1935). El duelo final a cuchillo entre Argüello y Carlos parece, entonces, un homenaje póstumo a ese criminal orillero de cuchillo, antes de que desaparezca del imaginario social y del cine argentino como figura contemporánea, y quede relegado, en cambio, al recinto de la nostalgia del 900 -tal como sucede con la versión de Torre Nilsson de Un guapo del 900 (1960)-. 
Esta transición y la desaparición del cuchillo como arma característica del criminal y de la lucha son incluso tematizadas en Monte criollo. Antes del duelo, Carlos está por sacar su revólver para enfrentarse a Argüello y éste le dice "no, como antes", y se baten a cuchillo. Estos dos momentos de los hombres y las armas están todavía presentes y coexisten, en parcial contradicción, en las películas de Mom, uno desapareciendo, el otro estableciendo su primacía. Esto es subrayado también en el comienzo de Palermo, cuando el cantante, vestido de modo caricaturesco como compadrito, burla en su canción al gaucho que lo había invitado a pelear con el facón. Es como si en "El Sur" Juan Dahlmann burlara al compadrito que lo había desafiado. Desaparece entonces el Azevedo de "La muerte y la brújula", el criminal orillero y de cuchillo, para dar lugar a los criminales como Red Scharlach, los gangsters que utilizan armas de fuego y automóviles. En el cine, al igual que en la prensa gráfica, también va cobrando primacía la figura del gangster, que maneja el revólver, la pistola e incluso la ametralladora (Setton, 2015, pp. 7-45). Esto muestra un ideario en torno al coraje y el crimen que está en discusión. Una película contemporánea como Lo que le pasó a Reynoso (1937), situada en el ámbito rural y dirigida por Leopoldo Torres Ríos, todavía exalta la figura del peleador a cuchillo. Esto se comprueba en la figura del resero Julián Reynoso, que cultiva la amistad y la nobleza rural, pero que, a diferencia de sus predecesores, trata de evitar hasta último momento la disputa y solamente en una circunstancia ineludible tiene que decidirse a pelear. La fuga (1937), situada también parcialmente en el mundo rural, toma en cambio distancia con gran agudeza de la representación idealizada del campo, y caracteriza al gangster de manera cómica como eficiente y querido maestro de una escuela rural, en nítido contraste con los gangsters de Mom o con el protagonista de Fuera de la ley.

Dentro de este marco, la mujer se presenta ahora, al menos parcialmente, por fuera de los tipos que la cinematografía argentina le había asignado. Lucy organiza, entonces, el camino hacia el negocio; en primer lugar, como el cerebro de la banda; y luego su camino junto con Carlos hacia la familia, pues ella traza el plan para lograr formar con él una familia -tal como ella misma afirma en un pasaje del film, lo va a convertir a Carlos en el hombre que ella sueña-. El plan es sencillo en su formulación, pero muy ambicioso en sus metas: transformarse ella misma para transformarlo a él.

El pasaje de un mundo a otro, del mundo del crimen al mundo de la familia, de la casa de juegos a la casa, está dado por un triple movimiento: hacia la maternidad, hacia la honestidad y hacia el desprendimiento económico, en contraste con el camino del progreso económico que condujo a la sociedad de los tres protagonistas hacia El Paraíso. El cerebro de Lucy los ha llevado al Paraíso, que en verdad no es más que un Purgatorio, y el corazón y el vientre de Lucy los llevará luego -a ella y a Carlos- al hogar, que en verdad es un Paraíso, y a Argüello, a la muerte. -Pues muchos son los llamados, pero pocos los escogidos-. En el camino de la honestidad, se deben respetar los afectos y a la gente honrada, pareciera decirnos la película, insertando así una distinción valorativa dentro del mundo criminal. ¡A un hombre como Mendieta no se lo engaña! Allí es cuando por primera vez Lucy se opone de manera frontal a los propósitos de Argüello. Los protagonistas masculinos que representan los contrincantes del villano Argüello, Carlos y Mendieta, son en este film algo así como calaveras simpáticos, algo semejante a lo que sucede con el protagonista de La Vuelta de Rocha (Romero, 1937b), son hombres "esencialmente" probos que se han desviado de su camino. Pareciera que las películas de la época quisieran alertar a los hombres contra las seducciones de las veleidades del tango, del juego y del coraje de los arrabales. Aquellas calaveradas medio ingenuas y medio simpáticas, el hecho de querer jugar a ser compadritos, podrían comprometer los sagrados valores familiares (pues este mundo ambiguo los lleva a jugarse el dinero que no les pertenece, la mujer que aman, y a poner en 
peligro el nombre, el honor y la constitución de la familia). La familia -y en general el círculo de los afectos- aparece, desde Perdón, viejita hasta Apenas un delincuente (Fregonese, 1949), como lo opuesto del crimen, hecho que cambia ya de manera radical en las películas de la Generación del 60, en El jefe, en Alias Gardelito o en Los venerables todos (Antín, 1962), películas en que los valores familiares ya se han desplomado por completo y el círculo familiar aparece como un ámbito decadente, ni siquiera como el ámbito de encierro sofocante que muestran muchos de los films de Torre Nilsson e incluso algunos de Christensen. En Monte criollo, en cambio, la familia es el lugar de la redención, como futuro transformador y esperanzador. Si en La Vuelta de Rocha y en la mayor parte de los films de la época la familia representa las buenas viejas tradiciones $-\mathrm{y}$ se trata por lo tanto de la familia de origen o procedencia- en Monte criollo, en cambio, es la familia construida, la familia de procreación, aquella que aparece como la posibilidad de redención. ${ }^{3} Y$ esta salvación se presenta como una especie de pacto entre los valores tradicionales y la transgresión a esos valores. Lucy debe ser fiel a su vínculo afectivo con Mendieta, representante de las familias honorables y adineradas, pero a la vez debe ahorrar el dinero mal habido para lograr construir una familia. El corte final y tajante con el "verdadero" delincuente, Argüello, aquel que no respeta las tradiciones ni las lealtades, es el paso necesario que les permite a Lucy y a Carlos ingresar al sagrado ámbito familiar y redimirse en la futura vida hogareña y la promesa del hijo en el vientre de Lucy.

A la presunta ingenuidad de los hombres buenos, que juegan a ser malos, se opone la audacia de las mujeres: Lucy salva a Carlos al reponer en la caja el dinero que él había robado luego de ser engañado como un incauto (Fig. 2), y ella misma engaña de este modo a Argüello y en parte también a Carlos (por su bien); de manera similar, Ana María engaña durante todo el film a Schweizer y a Adolfo Villanueva (también por su bien). A pesar de las apariencias, las mujeres son aquí las verdaderas fulleras, las que dominan la situación con audacia e incluso engaños. ${ }^{4}$ En ese sentido, discrepamos de la lectura de Elena Goity, quien considera que la configuración de los personajes femeninos reproducen los tipos ya establecidos de las mujeres en el cine:

En el universo gangsteril la mujer es un objeto más, otra cara posesión que pone de manifiesto la capacidad adquisitiva del tahúr. La figura de la blonda sexy, cubierta de sedas y pieles, amante de las joyas es un topos genérico. Más allá de su capacidad para simbolizar el éxito, a veces adquiere un papel activo y retribuye los favores recibidos, colaborando en las sesiones de juego o pasando información (Monte criollo, La fuga).

Con el correr del tiempo, la figura de la mujer se fue diversificando pero, aunque se amplió la tipología, raramente dejo de ser eso: un tipo. Figuras esquemáticas, claramente reconocibles, con funciones y aspecto prefijado, de inmediata decodificación. Para la construcción de los modelos femeninos también se recurre, como en la figura del gángster, a la confrontación y la bipolaridad. De esta manera se opusieron la morocha de buen corazón versus la rubia mala. (2000, pp. 405-406)

Como ya indicamos, en Monte criollo y en Palermo las mujeres no acompañan, deciden, emprender, planean y llevan a cabo las acciones necesarias para lograr sus objetivos, manipulando y engañando a los hombres si es necesario; a su vez, su destino es la maternidad, el amor y la fundación del hogar. De este modo, se puede ver con claridad que estas figuras combinan elementos que usualmente se han atribuido a "lo femenino" con otros que la tradición ha reservado a los personajes masculinos, por ejemplo los rasgos del fullero o del agente encubierto. 


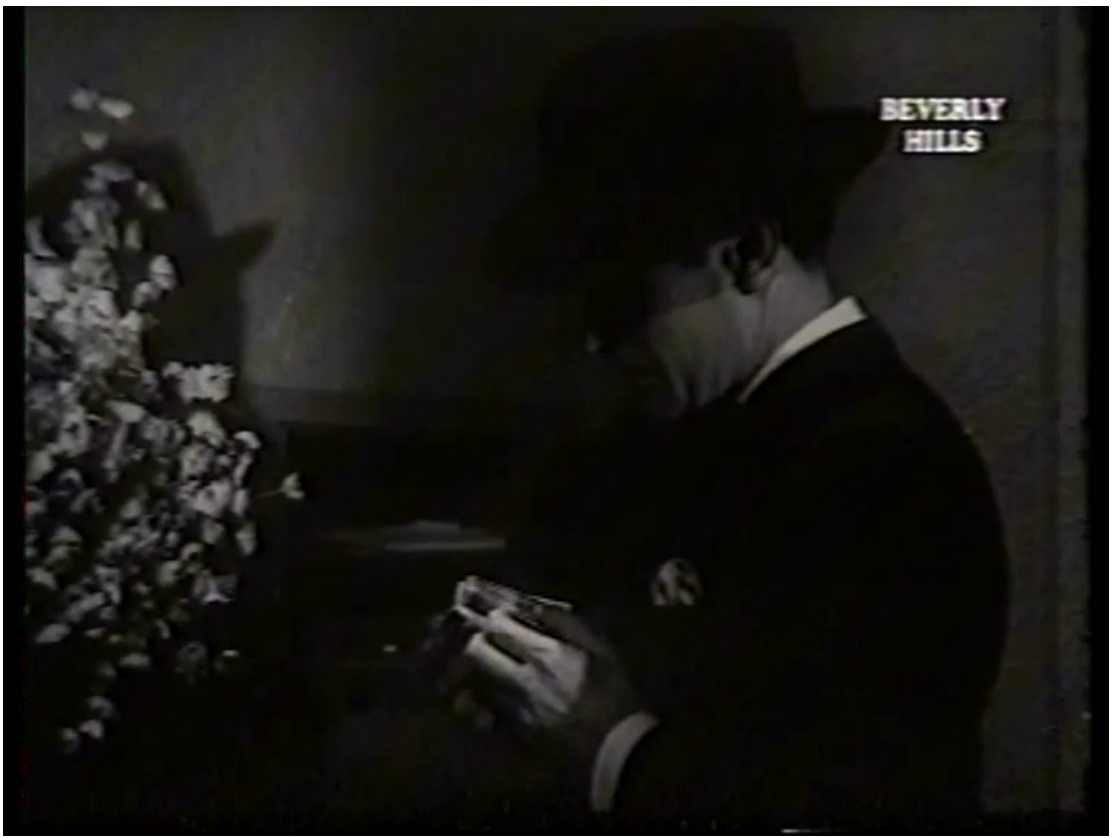

Figura 2. Carlos toma el dinero de la caja fuerte luego de ser engañado por Argüello y un cómplice (Monte criollo, 1935)

Caber señalar que estos dos policiales de Mom están narrados, en gran medida, desde la perspectiva del mundo del crimen -de un modo más marcado Monte criollo que Palermo, pero también esta última, y este hecho justifica que recién en el cierre del film descubramos, junto con los criminales y también junto con Adolfo, que Ana María es un agente encubierto de la policía-. Esto contrasta con los films policiales narrados desde la perspectiva de la ley, que promueven de manera evidente la eficacia de la policía visible y el restablecimiento del orden vigente, luego de la interrupción de ese orden por la aparición del crimen. Esta serie de películas, entre las que se encuentran Fuera de la ley, Historia de crímenes (Romero, 1942), Pasaporte a Río (Tinayre, 1948), El rufián (Tinayre, 1961), Deshonra (Tinayre, 1952), Apenas un delincuente -y en general la mayor parte de las películas policiales de Romero, Tinayre y Fregonese-, condena al infractor de manera clara y distinta y narra la historia desde la perspectiva de la policía o una muy próxima, por ejemplo la del periodista de policiales -en Apenas un delincuente y también en parte en La muerte camina en la lluvia (Christensen, 1948)-; aunque no llegan al extremo de presentar un orden por completo maniqueo y ofrecer una narración centrada en la obvia celebración de las fuerzas policiales, tal como sí sucede con algunas películas de Don Napy (Luis Napoleón Duclout), Captura recomendada (1950) y Camino al crimen (1951). ${ }^{6}$

Monte criollo, en cambio, narrada íntegramente desde el punto de vista criminal y por completo circunscripta al mundo del crimen, finaliza con un modo de justicia propio de ese ámbito. Cuando finalmente aparece la policía, Argüello afirma que él mismo se ha quitado la vida, y le niega a la ley positiva la posibilidad de cumplir con su deber. De este modo, y por la perspectiva 
de la narración, se niega la identificación de la ley positiva con la justicia, pues la ley tendría que encarcelar a Carlos, que -como sabe el espectador- ha matado a Argüello de manera justa, en buena ley. Este final es posible e incluso coherente gracias al imaginario criollista presente en el film, pues este implica un modo de justicia diferente y más elevado que el de la ley positiva, e incluso un criminal tan ruin como Argüello comparte los valores del coraje y esa justicia superior. Esto ya no sucede con el criminal gangsteril de Palermo, Schweizer, ni con Juan Robles (José Gola) en Fuera de la ley -quien aprende a ser criminal leyendo historias de Al Capone-. Estos últimos son, por el contrario, la contracara perfecta de todos los valores criollos: el honor, el respeto a la familia, la amistad, la consideración hacia las mujeres. Por eso en estas películas la justicia sí está identificada con la ley positiva del Estado, encarnada en Fuera de la ley en la figura del padre del criminal, el Comisario Robles (Luis Arata), funcionario ejemplar de la policía, y en Palermo, en Ana María y el resto del cuerpo de la policía, los policías visibles. Esto explica que, desde el comienzo, las películas planteen la necesidad de que la ley persiga y encuentre al criminal: en Palermo, a partir de las acciones de la policía; en Fuera de la ley, de manera simbólica por el juego de sombras con que comienza la película -las sombras de las rejas se proyectan sobre las sombras de los criminales, y en este sentido, la secuencia inicial puede ser leída como epítome de todo el film-.

En 1937 cambia de manera radical la figura del gangster en el cine argentino. Fuera de la ley y Palermo se estrenan ambas entre cuatro y cinco meses después del secuestro de Eugenio Pereyra Iraola (el 24 de febrero), quien poco tiempo después apareció muerto. La muerte del niño de la alta sociedad argentina conmovió profundamente al país. Tanto Mom como Romero abordan en estas películas el secuestro y en ambas aparece con claridad la posibilidad de la muerte del secuestrado (Juan Robles mata incluso a un niño en su intento de huida). Dentro de este contexto, sucede en las películas aquello que no sucedió en la realidad: las fuerzas de la ley evitan la muerte de la víctima y matan al criminal. En el marco de esta situación, la posibilidad de buscar la simpatía del público con el criminal era escasa, y el gangster aparece aquí representado de manera monolítica como un desalmado, alguien que atenta contra lo más sagrado (la familia, la alta sociedad). La amenaza contra la alta sociedad cobra mayor nitidez en Palermo. En Monte criollo, la figura de Mendieta, quien representa lo más alto y noble de la sociedad, aparecía ligeramente amenazada por las trampas de Argüello, pero en Palermo se trata de la amenaza a todo el Jockey Club. Schweizer pretende corromper lo mejor de la sociedad, "Palermo, el lugar de los señores, el lugar de los caballeros", como dice Adolfo, "que siempre sabrán defenderse contra los audaces" (en Mom, 1937).

En Monte criollo, Argüello, criollo todavía como Azevedo y no judío-extranjero como Schweizer o Scharlach, se redime y acepta sobre sí la culpa del crimen, sacrificándose como un criollo como lo hace Aniceto Reyes al final de Viento Norte (Soffici, 1937)-, como un hombre de ley. Hace pasar su muerte por un suicidio y muestra que, a pesar de todo, él también puede tener códigos -al menos cuando ya no le queda vida-. La habilidad con las manos, que caracteriza a la figura de Argüello, sigue la tradición propia del género, que la identifica con el engaño y la estafa, pero también con la destreza criolla del manejo del cuchillo; la variación más pronunciada respecto del género policial y de su tradición originaria -vinculada estrechamente con la novela gótica: La dama de blanco (Collins, 1974), Los elixires del diablo (Hoffmann, 1985), etc.- se produce en la resignificación de la voz, que encarnada ahora en el cantor de tangos ya no puede representar a las fuerzas del mal. En la novela gótica y el policial del siglo XIX, la seducción de la voz, la oratoria son características propias de los villanos, capaces de atraer a las mujeres y quitarles su fortuna. En Carlos también encontramos el poder de seducción de la voz, capaz de 
atraer a las mujeres. Como nos dice Lucy, "atraer a las mujeres es hacer negocios: las mujeres manejan el dinero del mundo" (en Mom, 1935), tal como sucede en muchas novelas góticas. Pero aquí la voz -atravesada por el ideario tanguero- ha sido ennoblecida: conserva su poder de seducción, pero el malvado maestro de la elocuencia del gótico se ha transformado en el noble cantor de tangos, que en la tradición nacional es en parte una derivación del payador (de Santos Vega), tal como es descrito en su evolución por Prieto (1988) y como lo vemos en la figura de Preludio en Perdón, viejita. La habilidad fullera, criolla de las manos podía tolerarse en 1935, incluso cuando intentaba hacer caer a Mendieta (la alta sociedad); después de la muerte del niño Iraola, el criminal pasa a ser radicalmente un Otro, de apellido extranjero, que hace negocios con los judíos prestamistas y atenta contra toda la sociedad. Hay también aquí una advertencia a los señores, a la alta sociedad, que deben defenderse, pues las debilidades de los Mendieta o Villanueva ponen en peligro al conjunto de la sociedad.

Por lo señalado hasta aquí, se puede ver que en las dos películas funciona una oposición entre los caballeros, que son finalmente los que forman familia con la heroína, y los miserables, los "verdaderos" criminales. A diferencia de otras tradiciones que explican el crimen a partir de las condiciones sociales o familiares, tal como sucede en parte en Apenas un delincuente o en Deshonra, aquí los "verdaderos" criminales están configurados a partir de peculiaridades esenciales individuales. Esto los convierte en villanos, en contraste con los "caballeros", los "falsos" criminales, quienes sólo contingentemente abren la puerta del mal, pero que en verdad son "caballeros", como Carlos y Adolfo.

En los dos héroes masculinos el problema es la afición al juego. Ambos, Carlos y Adolfo, son jugadores, jugadores que confían en que, finalmente, la suerte va a cambiar; pero la suerte no cambia, o al menos no cambia en el momento ni en el modo en que ellos creen. Pero ellos no dejan de ser caballeros -tal como subrayan de manera explícita los finales de las películas- ni cuando la suerte los traiciona y pierden todo. Entonces, como caballeros, se juegan la vida y no traicionan sus convicciones. Los delincuentes, en cambio, se definen precisamente por su villanía y por la falta de "caballerosidad"; son aquellos que quieren forzar el amor de las mujeres, no por la voz, sino por la violencia de las manos y las armas (Argüello en Monte criollo, Conrado Schweizer en Palermo, Peralta en Loco lindo, pero también Juan Robles en Fuera de la ley, Solari en La vuelta de Rocha y muy tempranamente José Gran en Nobleza Gaucha). Atentan contra la constitución de la familia y, en general, contra lo más elevado de la sociedad (que aquí se entiende en términos económicos y queda identificado por completo con la elevación moral). En estos villanos se unen dos objetivos precisos, la acumulación de dinero y "sacar del medio", tal como dice Schweizer, al rival, para quedarse con la mujer. En la tradición de las novelas fundacionales, la villanía está identificada con los parvenus, que pretenden forzar a las mujeres criollas, todas condensadas en las películas de Mom en la figura de Nedda Francy. Por eso, implican una amenaza a la sociedad.

Como ya señalamos, los hombres honrados e ingenuos deben aprender a poner límites a sus veleidades y a los villanos, pues ponen en riesgo lo más elevado. Como contrapartida la mujer en la figura de la madre o esposa aparece como la redención del hombre. En Monte criollo, el cantor de tangos debe fecundar a la mujer argentina y dejar de lado, así, los peligros propios y extranjeros. Y en Palermo el niño bien debe ser protegido por la mujer de ley (Ana María) y establecer una alianza de por vida con ella, el matrimonio. 


\section{CONCLUSIONES}

A lo largo del artículo se ha demostrado que las películas policiales de Mom se alejan de las figuras tradicionales de mujeres y sus personajes femeninos son bastante más complejos que las representaciones arquetípicas de la época. En contraste con la figura de la femme fatal propia del noir, ${ }^{7}$ que parecen encarnar al comienzo de los films, se revelan como mujeres redentoras. Son mujeres que descienden a los estratos morales más bajos para elevar a los hombres y a la sociedad; son, a la vez, mujeres que desempeñan papeles masculinos, y que solamente son fatales, en última instancia, para los criminales. Hay en esto una caracterización doble, ambigua y hasta casi esquizofrénica, pues, por un lado, pereciera que lo esencialmente femenino fuera la entrega al hombre que se ama y su sacrificio por ese hombre, pero, al mismo tiempo, se narra el modo en que la mujer domina la situación laboral y determina en gran medida los caminos y destinos de los personajes. A partir de una representación que sitúa a las mujeres en papeles tradicionalmente otorgados al hombre, Lucy organiza el negocio del juego y Ana María conduce la pesquisa.

En consonancia con eso, resulta también muy significativo que en ambas películas la protagonista femenina sea presentada huyendo, un personaje que escapa de la ley masculina, aunque después se muestre que ella es la ley auténtica y la verdadera esperanza de la sociedad. Para sacar al "hombre honrado" de sus vínculos con el crimen y construir así la familia y la sociedad futuras, el personaje femenino debe, en los dos casos, violar la seguridad de los ámbitos masculinos: ingresar en espacios masculinos y descifrar sus códigos y violentarlos. Tanto Ana María como Lucy abren la caja fuerte del villano, en un caso, para poner el dinero que Carlos había sacado; en el otro, para sacar los pagares de Adolfo en poder de Schweizer. Hacen esto para solucionar una cuestión vinculada con una deuda de dinero. De esta manera, ambas mujeres logran conquistar sus amores en estos negocios y formar su familia. Los criminales son, en ambos casos, aquellos que quieren apartar a las mujeres de su amor, Argüello y Conrado Schweizer. Y por lo tanto deben morir al final de la película, para dejar el camino libre para que se forme la familia en el seno de la ley, tal como lo han deseado y construido estas mujeres. ${ }^{8}$ 


\section{Bibliografía}

Antín, M. (Director) Garber, J. A. (Productor). (1962). Los venerables todos (cinta cinematográfica). Argentina: Nuevo Mundo.

Ayala, F. (Director), Olivera, H. y Ayala, F. (Productores). (1958). El jefe (cinta cinematográfica). Argentina: Aries Cinematográfica Argentina.

Blanco Pazos, R. y Clemente, R. (2004). Monte criollo. De La fuga a La fuga. El policial en el cine argentino. Buenos Aires: Corregidor, 2-3.

Borde, R. y Chaumeton, E. (1958). Panorama del Cine Negro. Traducción: Carmen Bonasso. Buenos Aires: Losange.

Borges, J. L. (1974). El Sur. En Obras completas (pp. 525-530). Buenos Aires: Emecé.

---- (1974) La muerte y la brújula. En Obras completas (pp. 499507). Buenos Aires: Emecé.

Cairo, H. Gunche, E. E. y Martínez de la Pera, E. (Directores y Productores). (1915). Nobleza Gaucha (cinta cinematográfica). Argentina: Productora Argentina de Films.

Christensen, C. H. (Director). (1948). La muerte camina en la lluvia (cinta cinematográfica). Argentina: Lumiton.

Christensen, C. H. (Director), Muñoz, G. (Productor). (1952). No abras nunca esa puerta (cinta cinematográfica). Argentina: Estudios San Miguel.

Collins, W. (1974). The Woman in White [La dama de blanco]. Edición de Julian Symons. Harmondsworth: Penguin.

Don Napy (Duclout, Luis Napoleón). (1950). Captura recomendada (cinta cinematográfica). Argentina: Julio O. Villareal.

---- (1951). Camino al crimen (cinta cinematográfica). Argentina: Luminarias.

----- (1952). Mala gente (cinta cinematográfica). Argentina: AS Cinematográfica.

Ferreyra, J. A. (Director). (1927). Perdón, viejita (cinta 
cinematográfica). Argentina: Unión Cinematográfica Argentina.

Fregonese, H. (Director) y Gutiérrez, J. (Productor). (1949). Apenas un delincuente (cinta cinematográfica). Argentina: Interamericana Films - Phoebus International.

Gaudreault, A. y François, J. (1995). El relato cinematográfico. Traducción: Núria Pujol. Barcelona: Paidós.

Goity, Elena (2000). Cine policial. Claroscuro y política. En C. España (dir.), Cine argentino. Industria y clasicismo 1933/1956 (vol. 2, pp. 400-473). Buenos Aires: Fondo Nacional de las Artes.

Hawks, H. (Director), Hughes, H. y Hawks, H. (Productores). (1932). Scarface (cinta cinematográfica). Estados Unidos: The Caddo Company y United Artists.

Hodara, M. y Darín, R. (Directores), Bossi, P., Bossi, C. y Buscarini, J. P. (Productores). (2007). La señal (cinta cinematográfica). Argentina: Pampa Films.

Hoffmann, E. T. A. (1985). Los elixieres del diablo [Die Elixieren des Teufels]. Sämtliche Werke in sechs Bänden. 6 tomos, 2/2. Edición de Wulf Segebrecht y Hartmut Steinecke, con la colaboración de Gerhard Allroggen, Friedhelm Auhuber, Hartmut Mangold y Ursula Segebrecht. Frankfurt am Main: Deutscher Klassiker,

Lafforgue, J. y Rivera, J. B. (1996). Asesinos de papel. Ensayos sobre narrativa policial. Buenos Aires: Colihue.

LeRoy, M. (Director), Wallis, Hal B. y Zanuck, D. F. (Productores). (1931). Little Caesar (cinta cinematográfica). Estados Unidos: Warner Bros.

Moglia Barth, L. J. (Director). (1933). Tango! (cinta cinematográfica). Argentina: Argentina Sono Film.

Mom, A. S. (Director). (1935). Monte criollo (cinta cinematográfica). Argentina: Argentina Sono Film.

---- (1936). Loco lindo (cinta cinematográfica). Argentina: Argentina Sono Film.

----- (1937). Palermo (cinta cinematográfica). Argentina: Argentina Sono Film.

Momplet, A. (Director). (1938). Turbión (cinta cinematográfica). Argentina: Estudios Río de la Plata. 
Murúa, L. (Director). (1962). Alias Gardelito (cinta cinematográfica). Argentina: Río Negro Producciones.

Prieto, A. (1998). El discurso criollista en la formación de la Argentina moderna. Buenos Aires: Sudamericana.

Romero, M. (Director). (1937a). Fuera de la ley (cinta cinematográfica). Argentina: Lumiton.

---- (1937b). La Vuelta de Rocha (cinta cinematográfica). Argentina: Lumiton.

----- (1942). Historia de crímenes (cinta cinematográfica). Argentina: Lumiton.

Saslavsky, L. (Director) y Arancibia, E. (Productor). (1937). La fuga (cinta cinematográfica). Argentina: Pampa Film.

Sebreli, J. J. (1997). Dashiell Hammett o la ambigüedad. En Escritos sobre escritos, ciudades bajo ciudades: 1950- 1997 (pp. 223-233). Buenos Aires: Sudamericana.

Setton, R. (2015). La literatura policial argentina entre 1910 y 1940. En Fuera de la ley: 20 cuentos policiales argentinos (19101940). Buenos Aires, Madrid: Adriana Hidalgo.

Soffici, M. (Director). (1937). Viento Norte (cinta cinematográfica). Argentina: Argentina Sono Film.

Soffici, M. (Director) y Olegario, F. (Productor). (1938). Prisioneros de la tierra (cinta cinematográfica). Argentina: Pampa Film.

Susini, E. (Director). (1933). Los tres berretines (cinta cinematográfica). Argentina: Lumiton.

Tarruella, R. (1992). Manuel Romero. Entierro y quema en el día de la primavera. En S. Wolff (coord.), Cine argentino. La otra historia (pp. 25-40). Buenos Aires, Editorial Letra Buena.

Tinayre, D. (Director), Saslavsky, L. y Tinayre, D. (Productores). (1948). Pasaporte a Río (cinta cinematográfica). Argentina: Argentina Sono Film.

Tinayre, D. (Director). (1961). El rufián (cinta cinematográfica). Argentina: Argentina Sono Film.

----- (1952). Deshonra (cinta cinematográfica). Argentina: Interamericana - Estudios Mapol. 
Torre Nilsson, L. (Director), Gaffet, N. y Torre Nilsson, L. (Productores). (1960). Un guapo del 900 (cinta cinematográfica). Argentina: Producciones Cinematográficas Ángel.

Torre Nilsson, L. (Director y Productor). (1972). La Maffia (cinta cinematográfica). Argentina: Litoral / Producciones Cinematográficas Litoral S.A.C.I.F.I.

Torres Ríos, L. (Director) y Joly, J. (Productor). (1937). Lo que le pasó a Reynoso (cinta cinematográfica). Argentina: Cinematográfica Terra.

Wellman, W. A. (Director) y Zanuck, D. F. (Productor). (1931). The Public Enemy (cinta cinematográfica). Estados Unidos: Warner Bros.

\section{NOTAS}

1. La figura de Miguelito es muy significativa dentro de la tradición del cine policial argentino por varios motivos. Aparentemente es el primer detective denominado expresamente de ese modo; es un detective que no pertenece a la policía, es decir, un individuo privado que comienza a hacer investigación por su cuenta, tal como sucede en la tradición de la literatura de enigma; a la vez, esta figura está emparentada con las figuras de Preludio en Perdón, viejita (Ferreyra, 1927) y con el Gaucho Juan, de Nobleza Gaucha (Cairo, Gunche, y Martínez de la Pera, 1915). Estos tres personajes hacen pequeños ensayos de pesquisas en crímenes vinculados con las mujeres que aman, y el Gaucho Juan hace, al igual que Miguelito, el viaje del "detective rural" a la ciudad. Ambos viajan para salvar su amada, y se repiten muchas de las acciones para lograr el objetivo. La diferencia principal radica en que la figura de Miguelito condensa en realidad a los dos personajes que van a la ciudad en Nobleza Gaucha, pues él es a un tiempo el detective amante, que se juega el pellejo para salvar a su prenda, y la figura cómica (que en Nobleza gaucha encarna el personaje de Don Genaro, interpretado por Celestino Petray). A pesar de esto, algunos críticos consideran la película, y no sin razón, solamente a medias como una película policial:

Solo puede incluirse un film como Loco lindo (1936) en el género policial por la presencia, en el argumento, de ciertos actos claramente delictivos. En este caso, el fraude político, el secuestro y el robo de ganado, ejecutados por matones al servicio de políticos venales. Por lo demás, la película está más próxima a la comedia sainetesca que al policial (...) Carmencita resulta, en definitiva, raptada por su pretendiente. Enterado de los hechos, Miguelito sale en su rescate pero, para costearse la vida, se emplea como detective al servicio de don Manuel en un frigorífico de Mataderos. Establecido allí y a pesar de sus prácticas de novato, logra desbaratar la banda de cuatreros y recuperar a su amada, quien luego de su hazaña, no duda en casarse con él. (...) Si no consideramos al film un exponente ortodoxo del género policial, es por el tono cómico que se le da al tema. (...) Miguelito, en su nuevo rol de hombre de 
confianza /investigador, estudia técnicas detectivescas en un manual y las pone en práctica, ridículamente, frente a un espejo en su pequeño cuarto de pensión. (Goity, 2000, pp. 435-436)

2. En este sentido, Argüello presenta rasgos característicos de los personajes del film noir y de la serie negra, de la que este cine ha heredado muchos de sus elementos característicos. Tal como ha señalado acertadamente Sebreli en relación con las novelas de Hammett, todas las asociaciones son contingentes y están amenazadas en todo momento por la traición; no hay solidez en ningún acuerdo y no puede haber sociedades duraderas:

Los duros están destinados a ser solitarios, sus relaciones con los demás no pueden dejar de ser contingentes y permanentemente amenazadas por la desconfianza y la traición. Las relaciones sin reciprocidad -en las que todos tratan y son tratados por los otros como objetos- no sólo se establecen con las víctimas, sino también con los cómplices: a las víctimas se las engaña, a los cómplices se los traiciona. (Sebreli, 1997, p. 230)

En este sentido, la caracterización de Sebreli de Hammett, que se puede extender a gran parte de la serie negra, coincide plenamente con la descripción del cine negro que hacen Borde y Chaumeton (1958), quienes subrayan "la inseguridad de las relaciones entre los individuos del hampa" (p. 16) así como los "lazos de dominación complejos y cambiantes" (p. 16) propios de estos films. "Es pues, sobre el plano de una afectividad de reacciones quizá efímeras, donde deberá buscarse la raíz de este "estilo»" (Borde y Chaumeton, 1958, p. 13).

3. No está presente en estas películas el conflicto entre la familia de origen o de orientación y la familia de procreación, un motivo central en tradición de las películas de gangsters y mafias.

4. En el mismo sentido se encuentra el siguiente parlamento de Lucy respecto de Carlos: "Es el gran amor de mi vida. La única esperanza de mi vida. Y me he propuesto arrancarlo de esta casa para siempre" (en Mom, 1935). Y el propio Carlos en otro diálogo con Lucy no puede más que darle la razón: "Deja que goce de mi vida, que a la larga voy a caer en tus manos otra vez" (Id.).

5. Respecto de Fuera de la ley, Rodrigo Tarruella ha esbozado una lectura en parte contraria a la nuestra y presenta al film en sintonía con la tradición de la serie negra:

Fuera de la ley no sólo es un filme dentro de la ley, sino que es un film de la ley, la apoteosis del paternalismo y del filicidio, tan representativa y profética de la historia como Invasión de Santiago, su contrapartida ideológica. Arata policía ampara, protege, disculpa o hace la vista gorda ante la carrera criminal de su hijo, un Gola terriblemente malo. En el trágico final Arata abate a Gola. Formalmente, el filme impresiona. Es la única película cuidada de Romero, lo cual le da un carácter extraño de filme aislado, inclusive dentro del cine argentino. Hay una crueldad inusual, predominio de la imagen y diálogos secos y cortantes en la mejor tradición de la "serie negra», apartándose del parloteo incesante de una obra que niega sistemáticamente el silencio. Romero pasa insólitamente a la acción narrando por primera, y casi única vez, con soltura. Los notables encuadres están totalmente influidos por Dreyer. (Tarruella, 1992, p. 31) 
6. En relación con Don Dapy, es válida, al menos parcialmente, la afirmación de Goity:

Las realizaciones de Don Napy, que se centran en casos policiales resueltos por el oficial Campos, son un claro ejemplo de ello. La historia se cuenta desde la óptica de la ley, y se enaltece a las figuras del orden, alcanzando extremos de adulación. (Goity, 2000, p. 409)

Sin embargo, esto no es enteramente cierto, pues no sucede así con la película policial Mala gente (1952), en que está ausente la figura del oficial Campos y casi faltan por completo las autoridades policiales, e incluso el punto de vista está situado en el del mundo criminal.

7. En Mom se puede advertir una gran conciencia de los géneros e incluso un trabajo paródico con ellos: solamente por dar un ejemplo, vale la pena recordar que uno de los personajes secundarios de Palermo se despide con la frase inglesa so long, que aparece en varios films policiales tempranos, por ejemplo, The Public Enemy (Wellman, 1931). Este recurso reaparecerá muchísimos años después en otra película que pretende honrar, de manera muy tardía, al género, La señal, 2007, de Hodara, M. y Darín, R.

8. En toda la tradición temprana de las películas de gangsters, el protagonista suele ser de una misoginia muy visible y en general se opone de manera violenta al enlace matrimonial de su amigo -Scarface (Hawks, 1932); The Public Enemy (Wellman, 1931) y Little Caesar (LeRoy, 1931). 
